Volume 1, Issue 2, 2011, 064-071

Received: 20.02.2011 / Accepted: 21.03.2011 / Published on-line: 15.04.2011

\title{
Hybrid nanostructurated material for biomedical applications
}

\section{Crina Saviuc ${ }^{1}$, Alexandru Mihai Grumezescu ${ }^{2 *}$, Alina Holban ${ }^{1}$, Carmen Chifiriuc ${ }^{1}$, Dan Mihaiescu $^{2}$, Veronica Lazar ${ }^{1}$}

\begin{abstract}
The purpose of this study was to assess the antibacterial activity of a novel hybrid organic-inorganic nanostructurated material based on $\mathrm{Fe}_{3} \mathrm{O}_{4} / \mathrm{PEG}_{600} /$ Citrus maxima essential oil. The core/shell material was synthesized by reacting $\mathrm{PEG}_{600}$ with $\mathrm{Fe}_{3} \mathrm{O}_{4}$ nanoparticles, under microwave condition. The core/shell was modified by adsorbtion of C. maxima essential oil as an extra-shell. The nanostructurated material was characterized by HR-TEM and FT-IR. The hybrid nanomaterial was screened for their in vitro antimicrobial activity against Gram - positive and Gram-negative bacterial strains. The in vitro assay of the influence of the magnetic biomaterial on bacterial adherence to cellular and acellular substrata and biofilm development demonstrated that novel hybrid nanostructurated materials could be used for the development of novel antimicrobial materials with anti-adherent properties.
\end{abstract}

Keywords: C. maxima, core/shell, hybrid nanostructured biomaterial, antibiofilm, antimicrobial activity

\section{Introduction}

As biomaterials are defined as any matter, surface, or construct interacting with biological systems, they have a great potential for biomedical applications. The biomaterials are used for the design of medical devices that replace parts or substitute functions of living systems and are intimately related with their tissues. To date, biomaterials are used clinically and experimentally in the field of implantology, drug delivery, extracorporeal blood separation columns and so on. The materials meant for assisting in any course of medical treatment are routinely being made up of many different types of surfaces. The medical device surfaces may act as a substrate for microbial attachment, the initial step in colonization and biofilm formation [1].

Despite the beneficial role of biofilms in environmental technologies and bioprocesses, they can be detrimental to both human life and industrial processes by causing infections, food and water contamination, biofouling etc. $[1,2]$. Antibiotic recalcitrance/tolerance is the major obstacle faced by the medical community in regard to biofilm related infections, several well-recognized puzzles in microbiology remained unsolved for decades deriving from this, i.e. latent bacterial infections,

\footnotetext{
${ }^{1}$ University of Bucharest, Faculty of Biology, Microbiology Department

*Corresponding author e-mail address: grumezescu@yahoo.com

${ }^{2}$ University Politechnica of Bucharest, Faculty of Applied Chemistry and Materials Science, Organic Chemistry Department
} 
unculturable microorganisms, persister cells and difficult treatment. Approximately $70 \%$ of bacterial strains frequently associated with nosocomial infections are resistant to at least one of the drugs commonly used to treat them [3]. For any medical device the infection related complication represents a risc factor which cannot be controlled and affects the performance of the device [4].

The continuous emergence of microbial resistance to existing antibiotics and the decline in the formulation of new one have generated an increasing interest in herbal medicines with anti-infective potential [2]. Essential oils are complex multicompound mixtures originating from plants, well known for their multiple biological activities, including their antimicrobial properties [5].

The purpose of this study was to quantify the antimicrobial and antibiofilm activity of a novel hybrid inorganic/organic material based on Citrus maxima essential oil.

\section{Experimental section}

\subsection{Extraction and characterization of $C$. maxima essential oil}

C. maxima epicarp, fresh samples was manually grounded and hydrodistilled in a Neo-Clevenger type apparatus performing a simple microwave assisted extraction. Chemical composition was settled by GC-MS analysis. Gas chromatographic analysis was performed using an Agilent 6890 Series GS System gas chromatograph fitted with a splitless injector for a low background with an injector liner split/splitless under a column head pressure of $12.5 \mathrm{psi}$ and $\mathrm{H}_{2}$ as carrier gas at a flow rate of $1.2 \mathrm{ml} / \mathrm{min}$. Oven temperature was programmed from 50 to $300{ }^{\circ} \mathrm{C}$ at $5{ }^{\circ} \mathrm{C} / \mathrm{min}$. Injector and detector temperatures were $250{ }^{\circ} \mathrm{C}$. A capillary column DB5-MS fused-silica J\&W Scientific Inc. $(30 \mathrm{~m} \times 0.25 \mathrm{~mm}$ i.d.; $0.25 \mu \mathrm{m}$ film $)$ was used. Detection was carried out with a 5973 mass-selective single quadrupole detector (Agilent technologies). Operation control and the data process were carried out by Agilent Technologies ChemStation software (Santa Clara, CA, USA). The mass spectrometer was calibrated before use with perfluorotributylamine (PFTBA) as a calibration standard. Identification of the chromatogram peaks as well as quantification of the compounds was performed following the methodology previously described $[6,7]$.

\subsection{Synthesis and characterization of hybrid nanostructurated biomaterial}

Nanoparticles of $\mathrm{Fe}_{3} \mathrm{O}_{4}$ were synthesized by hydrolysis in an aqueous solution containing ferrous and ferric salts with $\mathrm{KOH}$. The dimensions of $\mathrm{Fe}_{3} \mathrm{O}_{4}$ nanoparticles were in the 5-10 $\mathrm{nm}$ range and they were previously characterized by High Resolution Transmission Electron Microscopy [8-11].

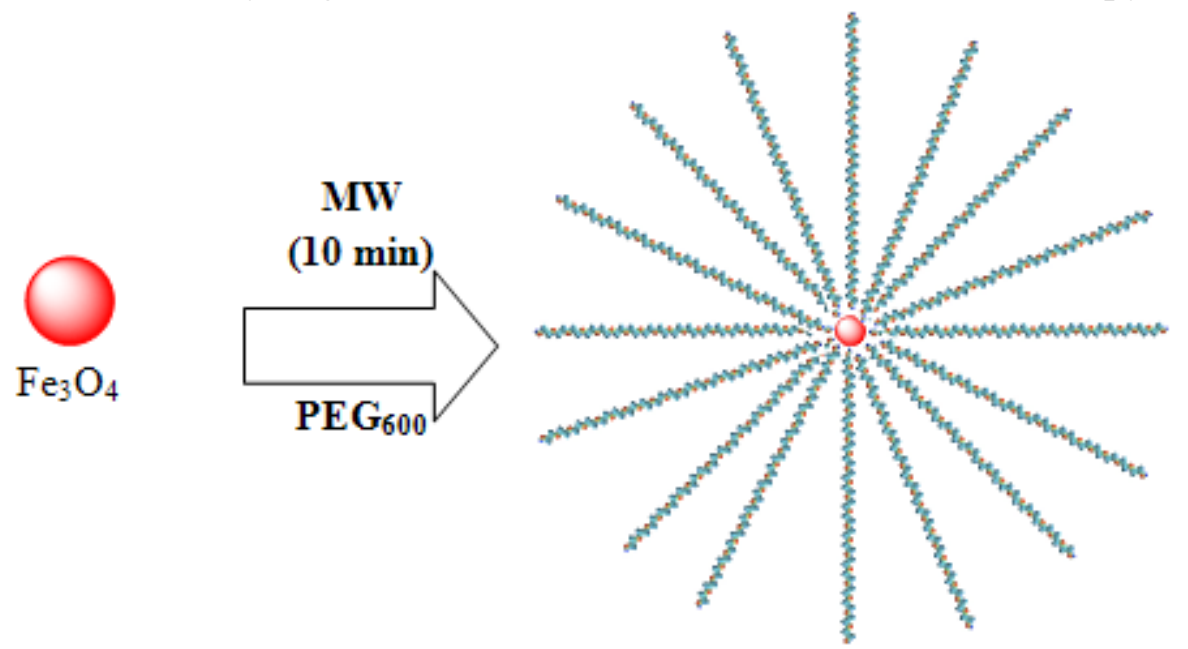

Figure 1: Synthesis of core/shell under microwave condition 
Core/shell nanoparticles (fig. 1) have been synthesized under microwave conditions [8-11]. The $\mathrm{Fe}_{3} \mathrm{O}_{4} / \mathrm{PEG}_{600}$ hybrid nanomaterial was characterized by FT-IR. IR spectroscopic measurements were performed using a Nicolet 6700 spectrometer provided with a ZnSe crystal based ATR module. The spectra were recorded over the wavenumber range of $650-4000 \mathrm{~cm}^{-1}$ with a resolution of $4 \mathrm{~cm}^{-1}$ for $\mathrm{Fe}_{3} \mathrm{O}_{4}$ as well as $\mathrm{Fe}_{3} \mathrm{O}_{4} / \mathrm{PEG}_{600}$. Essential oil of $C$. maxima has been adsorbed on the surface of nanostructured material as an extra-shell (fig. 2). The excess of the essential oil was removed by applying a magnetic field and washing with hexan. The hybrid nanostructurated material was dried at $30^{\circ} \mathrm{C}$ over night.

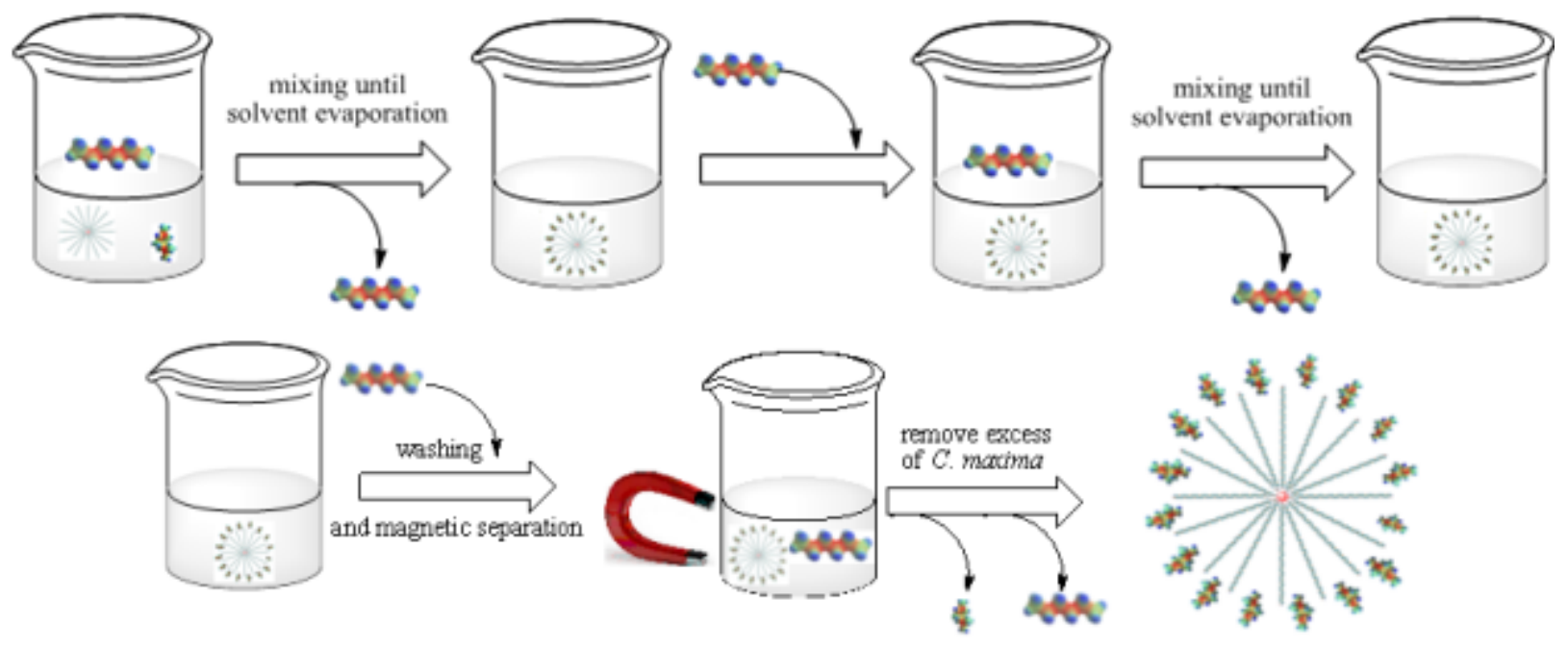

Legend:

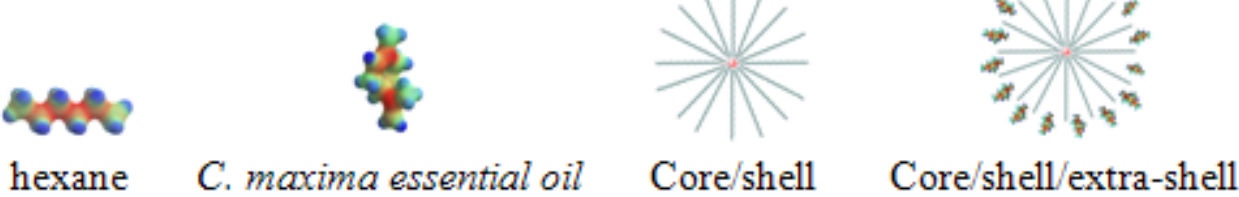

Figure 2: Schematic representation of extra-shell adsorbtion on hybrid nanostructurated material

\subsection{Assessment of the antibacterial activity of the essential oil}

Collection as well as recently isolated from clinical specimens bacterial strains were used for assessing the antimicrobial effect, belonging to the following species: Staphylococcus aureus ATCC 25923, Staphylococcus aureus MRSA 1684, Enterococcus faecalis ATCC 29212, Enterococcus faecalis 86, Escherichia coli ATCC 25922, Escherichia coli ESBL 1586, Klebsiella pneumoniae 1771.

The antibacterial activity of $C$. maxima essential oil was quantified by a kill-time curve method. Microbial suspensions performed in liquid medium ( $\mathrm{MH}$ broth) were left in contact with the essential oil diluted with dimethyl sulfoxide (DMSO) $(1: 1, \mathrm{v} / \mathrm{v})$ up to 30 minutes. The obtained inocula where seeded thereafter onto solid medium (MH) after 1, 3, 5, 15 and 30 minutes of contact, incubated at $37^{\circ} \mathrm{C}$ for $24 \mathrm{~h}$ in order to perform the viable cell counts. The assessment of bacterial strains susceptibility to nanoparticles impregnated with essential oil was performed by following the minimum inhibitory concentration (MIC) protocol using liquid medium twofold microdilutions in 96 multi-well plates.

\subsection{Bacterial strains adherence on inert and cellular substratum}

$\mathrm{CV}$ (violet crystal) staining technique was used for quantifying bacterial strains adherence to the inert substratum represented by the plastic wells. Negative controls for nanoparticles and DMSO where used. After performing the MCI protocol, the wells were subsequently emptied, washed 3 times with PBS (phosphate buffered saline), fixed with cold methanol and stained with CV 1\% 
solution for $30 \mathrm{~min}$. The biofilm formed onto the plastic wells was resuspended in $30 \%$ acetic acid and the intensity of the colored suspension was assayed by measuring the absorbance at $490 \mathrm{~nm}[10$, 12].

For the assessment of bacterial adherence on cellular substratum a modified Cravioto method (Cravioto, 1979) was used [1]. HeLa cells were routinely grown on 6 multi-well plates in MEM enriched with $10 \%$ heat-inactivated $\left(30 \mathrm{~min}\right.$ at $\left.56^{\circ} \mathrm{C}\right)$ fetal bovine serum (Gibco BRL), 0.1mM nonessential amino acids (Gibco BRL), and supplemented $0.5 \mathrm{~mL}$ of gentamycin $(50 \mu \mathrm{g} / \mathrm{mL})(\mathrm{Gibco}$ $\mathrm{BRL}$ ) and incubated at $37^{\circ} \mathrm{C}$ for $24 \mathrm{~h}$. HeLa cells monolayers grown in 6 multi-well plastic plates were used at $80 \%$ confluency. Essential oil impregnated nanoparticules suspensions in liquid medium $(\mathrm{MH})(5 \mathrm{mg} / \mathrm{mL})$ where obtained, seeded with $0.5 \mathrm{McF}$ arland bacterial suspensions for each strain and incubated for 5 hours. For the adherence assay, the HeLa cell monolayers were washed 3 times with PBS and $1 \mathrm{~mL}$ MEM medium and $100 \mu \mathrm{L}$ from the obtained cultures where added. The inoculated plates were incubated for $2 \mathrm{~h}$ at $37^{\circ} \mathrm{C}$. After incubation, the monolayers were washed 3 times with PBS, fixed with cold methanol and stained with Giemsa stain solution (1:20). The plates were washed, dried at room temperature overnight, and microscopically examined.

\section{Results section}

\subsection{GC-MS analysis of $C$. maxima essential oil}

There were performed two extractions and the average yields of essential oil (v/w \%) normalized to total plant mass (fresh weight) were $0.97 \%$ and $1.01 \%$ respectively. The main components found in essential oil of C. maxima epicarp were: limonene and $\beta$-pinene, with 74.878 and $21.267 \%$ from the total aria.

Table 1: Identification of compounds by GC-MS and Kovats index

\begin{tabular}{c|c|c|c|c}
\hline Peak & $\mathrm{T}_{\mathrm{R}}$ & $\%$ & Compound & identification*[6,7] \\
\hline 1 & 6.696 & 0.284 & $\alpha$-pinene & RI, MS \\
\hline 2 & 7.255 & 21.267 & $\beta$-pinene & RI, MS \\
\hline 3 & 8.374 & 74.878 & Limonene & RI, MS \\
\hline 4 & 8.97 & 0.203 & (E)-ocimene & RI, MS \\
\hline 5 & 10.545 & 0.053 & Linalool & RI, MS \\
\hline 6 & 14.747 & 0.124 & Citral & RI, MS \\
\hline 7 & 18.234 & 0.056 & geranyl acetate & RI, MS \\
\hline 8 & 19.623 & 0.074 & $\beta$ - caryophyllene & RI, MS \\
\hline 9 & 20.66 & 0.036 & Farnesene & RI, MS \\
\hline 10 & 21.232 & 0.722 & $\delta$-Elemene & RI, MS \\
\hline 11 & 28.828 & 1.254 & Nootkatone & RI, MS \\
\hline \multicolumn{2}{|c|}{ Total } & 98.951 & \multicolumn{2}{c}{} \\
\hline
\end{tabular}

*MS: Identification by NIST MS library, RI: Identification by Kovats index

\subsection{Fourier Transform infrared spectroscopy (FT-IR) characterization of hybrid organic/inorganic nanomaterial}

In Figure 3 the IR spectrum of $\mathrm{Fe}_{3} \mathrm{O}_{4}$ and $\mathrm{Fe}_{3} \mathrm{O}_{4} / \mathrm{PEG}_{600}$ are presented. The main absorption bands of $\mathrm{Fe}_{3} \mathrm{O}_{4} / \mathrm{PEG}_{600}$ are: $845,944,1093,1248,1348,1451,2865$ and $3454 \mathrm{~cm}^{-1}$. 


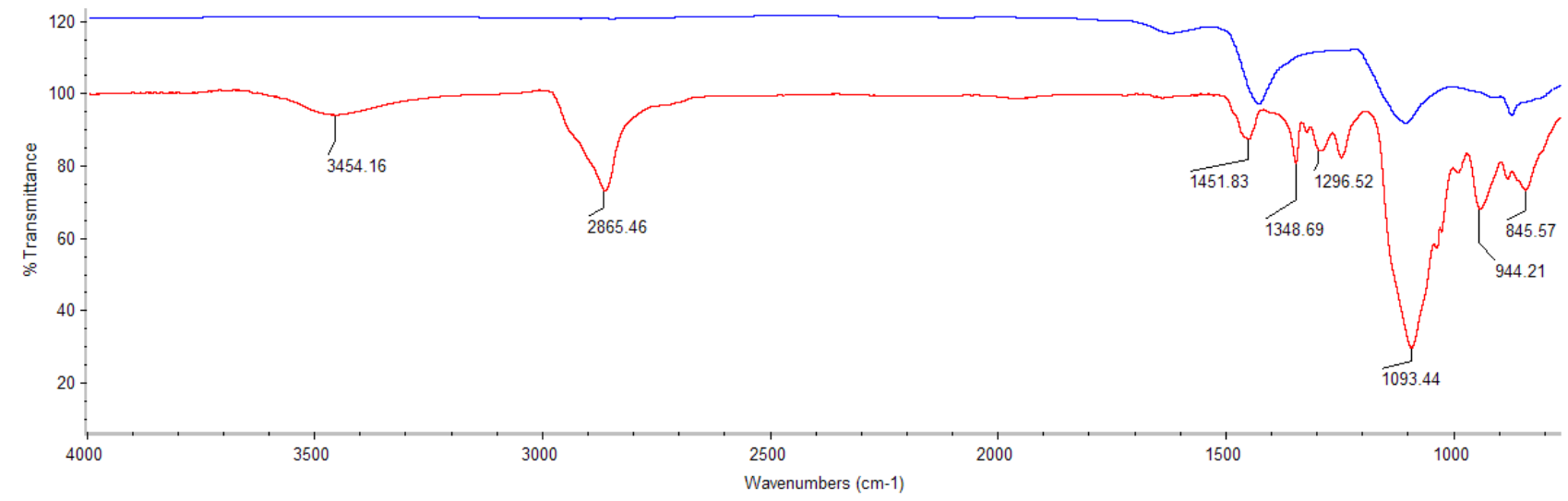

Figure 3: FT-IR spectra of $\mathrm{Fe}_{3} \mathrm{O}_{4}$ (blue line) and $\mathrm{Fe}_{3} \mathrm{O}_{4} / \mathrm{PEG}_{600}-$ core/shell (red line)

\subsection{Antibacterial activity of the essential oil.}

The essential oil exhibited a low antibacterial activity on the tested strains. The earliest and most evident bactericidal effect was obtained for E. coli ATCC 25922. For S.aureus and E. faecalis strains a growth inhibition effect was noticed (fig. 4).

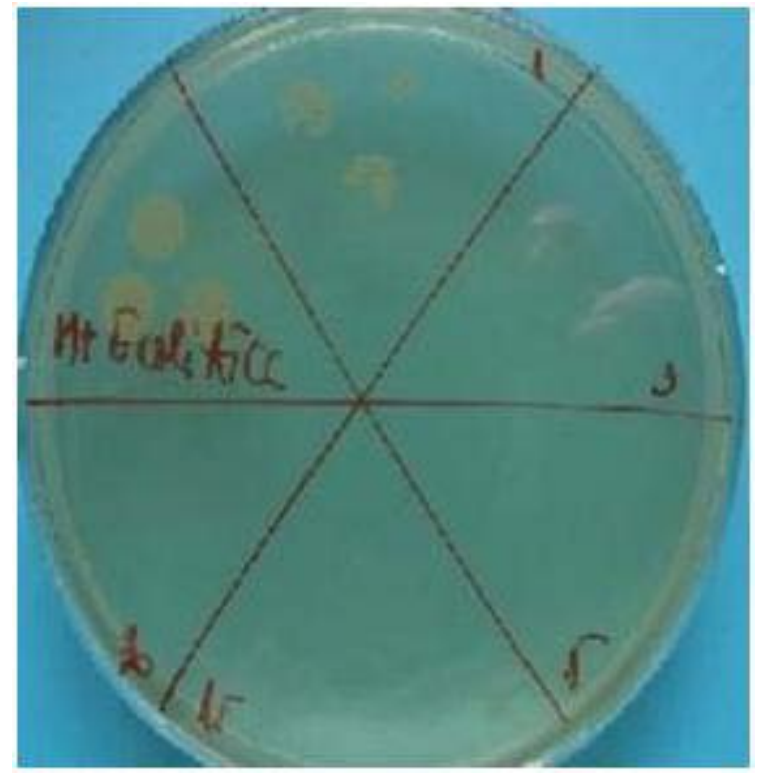

Figure 4: Early bactericidal effect of the C. maxima essential oil on the E. coli ATCC strain

\subsection{Bacterial adherence on inert substrata.}

The quantitative assay of the antimicrobial activity (MIC protocol) revealed that the essential oil impregnated nanoparticules exhibited a low MIC $(0.072 \mathrm{mg} / \mathrm{mL})$ only against E. faecalis 86 , for the other strains the microbial growth being slightly stimulated by the tested materials (fig. 5). An inhibition of bacterial adherence to the inert substratum was observed for the E. coli ESBL 1586, E. coli ATCC and the two E. faecalis tested strains, but suprinsingly, no dose-effect correlation could be established, the antibiofilm activity being noticed at an intermediary concentration $(0.03 \mathrm{mg} / \mathrm{mL})$ (fig. 6). The high concentrations of the nanoparticles slightly stimulated the bacterial adherence to the inert substratum. These results are supported by the microscopic examination data, showing that suspended essential oil impregnated nanoparticles proved to be a preferential support for the bacterial adherence, forming mixed aggregates, that either adhered to the plastic wells or offered an enlarged surface for bacterial growth in suspension phase, the growth rate exceeding the potential 
antimicrobial activity of the essential oil, as reflected in the low antimicrobial activity revealed by the MIC assay.

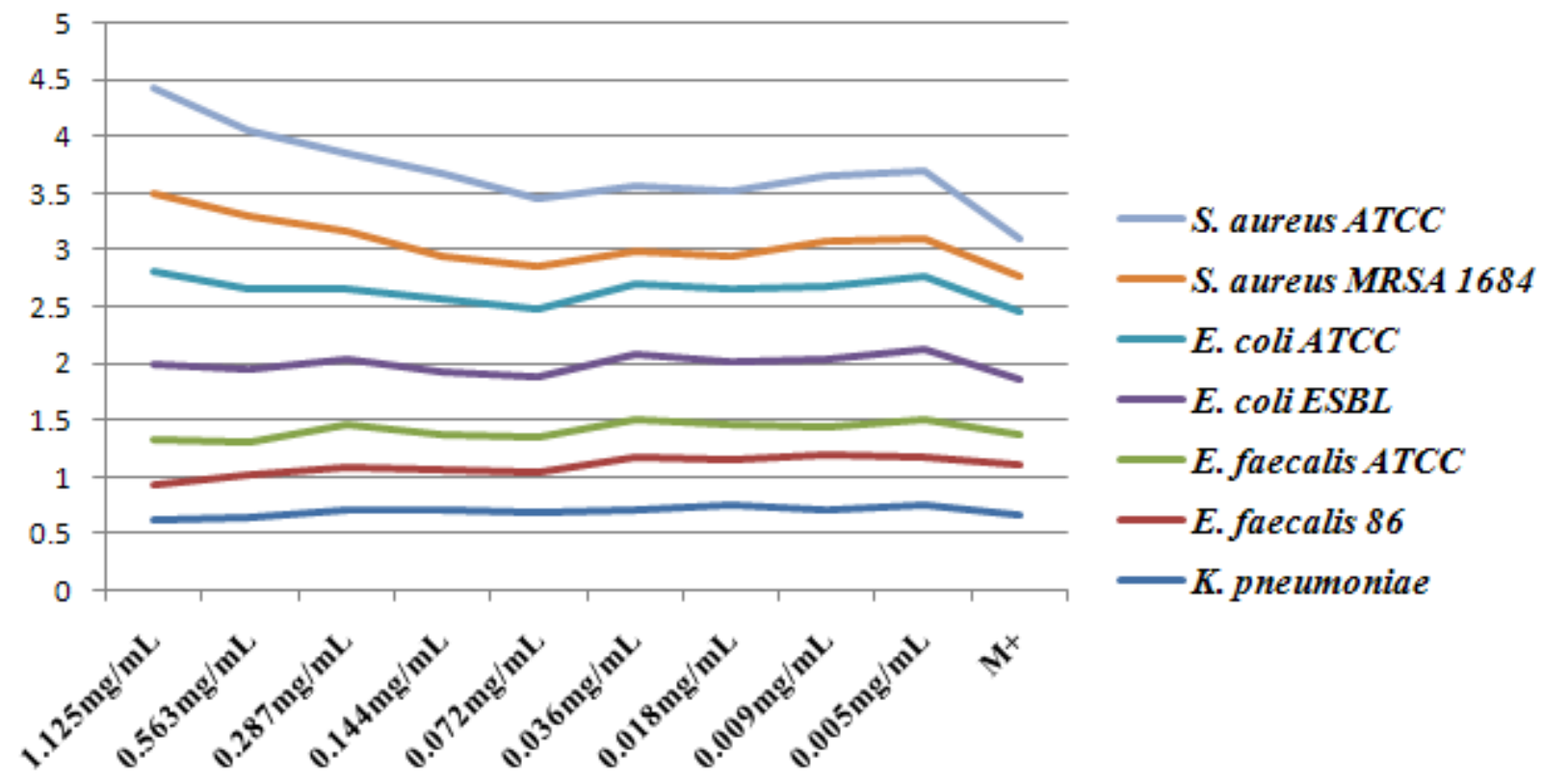

Figure 5: Influence of hybrid nanostructurated material on the microbial growth rate of different bacterial strains (M+- positive control, i.e. liquid medium seeded with bacterial inocula)

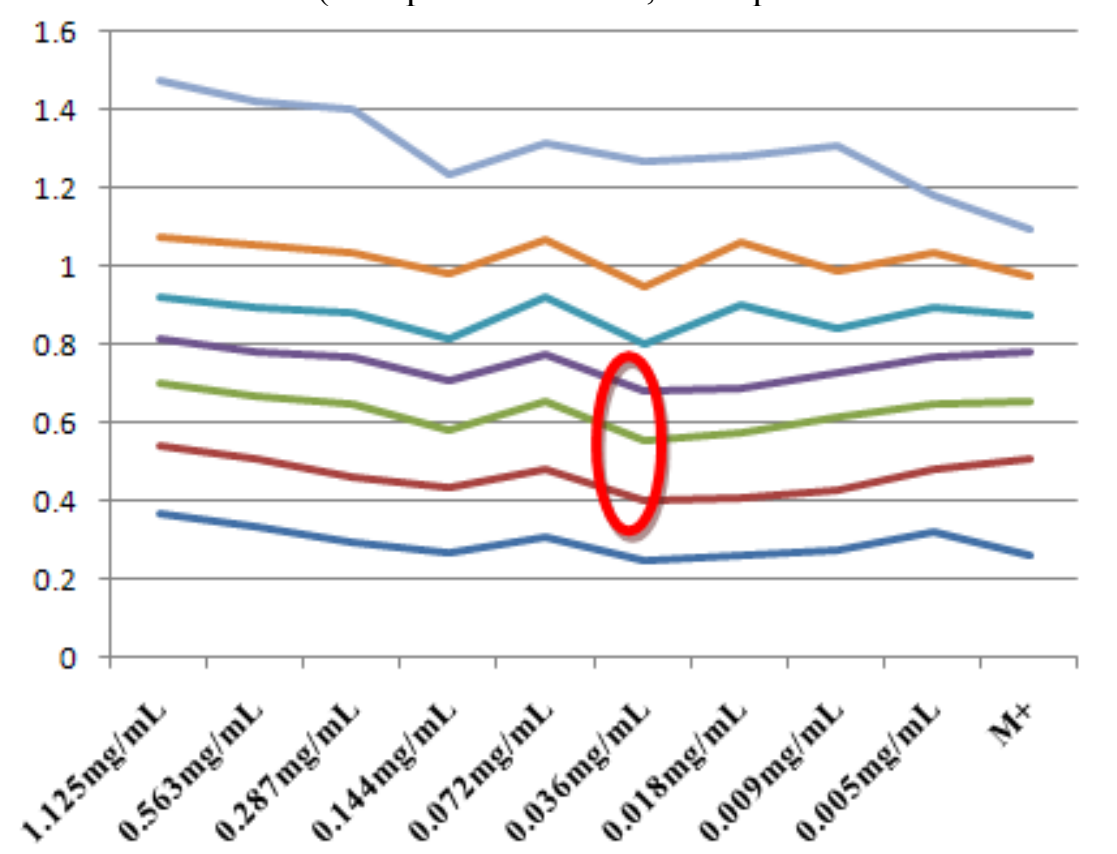

S. aureus ATCC

-S. aureus MRSA 1684

- E. coli ATCC

E. coli ESBL

E. faecalis ATCC

E. faecalis 86

- K. pneumoniae

Figure 6: Influence of hybrid nanostructurated material on the microbial strains ability to develop biofilms on the inert substratum represented by plastic wells $(\mathrm{M}+$ - positive control, i.e. liquid medium seeded with bacterial inocula)

\subsection{Adherence on cellular substrata}

The tested bacterial strains formed aggregates with the impregnated nanoparticles, showing a reduced ability to adhere to the cellular substrata. However, when present, a diffuse aggregative adherence pattern to the HeLa cells was observed (fig. 7). 


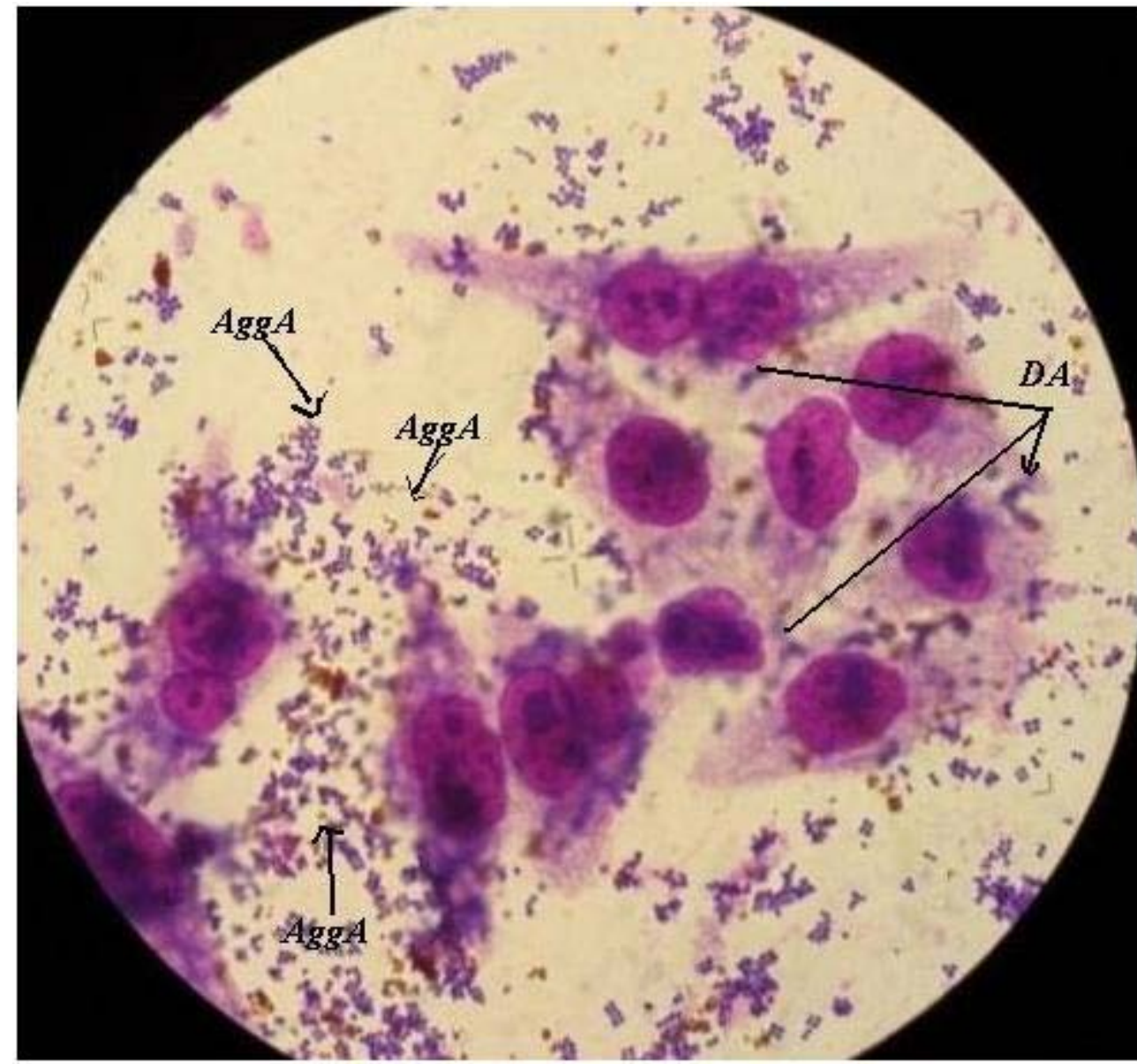

Figure 7: Microscopic image of the HeLa cells monolayer infected with bacterial cultures (S. aureus ATCC 25923) obtained in liquid medium containing essential oil impregnated nanoparticles (Giemsa staining, immersion oil, $\mathrm{x} 1000)$

\section{Conclusions}

Microwave-assisted hydrodistillation proved to be a better method for essential oils extraction in terms of yield and time of extraction comparing with previously tested simple extraction technique. The obtained hybrid nanostructured biomaterial exhibited a low antimicrobial activity. The antibiofilm activity is dependent on the suspended nanostructured biomaterial concentration and the tested strain. The microbial adherence to the inert substratum was inhibited by average concentrations of nanoparticles only in case of E. coli and E. faecium strains, while the adherence to the cellular substratum was inhibited for all tested strains, irrespective to the nanoparticles concentration. Our results recommand the hybrid inorganic/organic nanomaterial with low concentrations of active compounds matrix for obtaining medical devices formulations with antiadherence surfaces.

\section{References}

[1] Lazăr, V., “Aderența microbiană”, Editura Academiei Române, Bucureşti, 2003 
[2] Burt S., Essential oils: their antibacterial properties and potential applications in foods - a review. International Journal of Food Microbiology, 94, 223-253, 2004

[3] Tamilvanan Shunmugaperumal, Biofilm Eradicationand Prevention A Pharmaceutical Approach to Medical Device Infections, John Wiley \& Sons. Inc. Publication, U.S.A., 2010

[4] Hüsnü Can Bașer K., Buchbauer G.,"Handbook of essential oils. Science, Technology and Applications”, CRC Press, London, 2010

[4] Lemon, J. E., Schoen, J.,"Biomaterials science: an introduction to materials in medicine”, Elsevier Academic Press, U.S.A., 2004

[5] Hüsnü Can Bașer K., Buchbauer G.,"Handbook of essential oils. Science, Technology and Applications”, CRC Press, London, 2010

[6] Singh P., Shukla R., Prakash B., Kumar A., Singh S., Mishra P. K., Dubey N. K., Chemical profile, antifungal, antiaflatoxigenic and antioxidant activity of Citrus maxima Burm. and Citrus sinensis (L.) Osbeck essential oils and their cyclic monoterpene, DL-limonene, Food and Chemical Toxicology, 48, 1734-40, 2010

[7] Espina L., Somolinos M., Lorán S., Conchello P., García D., Pagán R., Chemical composition of commercial citrus fruit essential oils and evaluation of their antimicrobial activity acting alone or in combined processes, Food Control, 22, 896-902, 2011

[8]Buteică A. S., Mihaiescu D. E., Grumezescu A. M., Vasile B. S., Popescu A., Călina D., Mihaiescu O. M., The cytotoxicity of (non)magnetic nanoparticles tested on Escherichia coli and Staphylococcus aureus, Digest Journal of Nanomaterials and Biostructures, 5, 3, 651, 2010

[9]Buteică A. S., Mihaiescu D. E., Grumezescu A. M., Vasile B. S., Popescu A., Mihaiescu O. M., Cristescu R., The anti-bacterial activity of magnetic nanofluid: $\mathrm{Fe}_{3} \mathrm{O}_{4}$ /oleic acid/cephalosporins core/shell/adsorptionshell proved on $S$. aureus and E. coli and possible applications as drug delivery systems, Digest Journal of Nanomaterials and Biostructures, 5, 4, 927, 2010

[10] Chifiriuc M.C., Lazar V., Bleotu C., Calugarescu I., Grumezescu A.M., Mihaiescu D. E., Mogoşanu D. E., Buteica A.S., Buteica E., Bacterial adherence to the cellular respectively inert substrate in the presence of magnetic $\mathrm{CoFe}_{2} \mathrm{O}_{4}$ and $\mathrm{Fe}_{3} \mathrm{O}_{4}$ /oleic acid - core/shell nanoparticle, Digest Journal of Nanomaterials and Biostructures, 6, 1, 37-42, 2011

[11] Grumezescu A. M., Mihaiescu D. E., Mogoşanu D. E., Chifiriuc M. C., Lazăr V., Călugărescu I., Trăistaru V., In vitro assay of the antimicrobial activity of $\mathrm{Fe}_{3} \mathrm{O}_{4}$ and $\mathrm{CoFe}_{2} \mathrm{O}_{4}$ / oleic acid - core/shell on clinical isolates of bacterial and fungal strains, Optoelectronics and Advanced Materials - Rapid Communications, 4, 11, 1798 - 1801, 2010

[12] Saviuc C., Dascãlu L., Chifiriuc M.C., Rãdulescu V., Oprea E., Popa M., Hristu R., Stanciu G., Lazãr V., The inhibitory activity of Pomelo essential oil on the bacterial biofilms development on soft contact lenses, Romanian Archives of Microbiology and Immunology, 69, 3, 140-145, 2010 